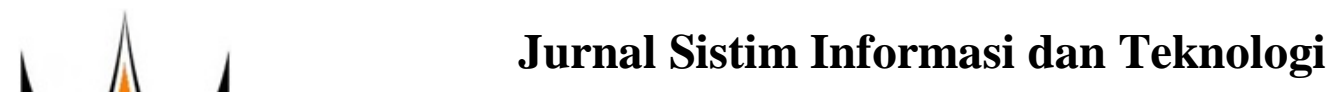

https://jsisfotek.org/index.php

2021

Vol. $3 \quad$ No.4

Hal: $281-287$

e-ISSN: 2686-3154

\title{
Simulasi dalam Optimalisasi Pengadaan Barang menggunakan Metode K-Mean Clustering
}

\author{
Indah Savitri Hidayat $^{1 \bowtie}$, Sarjon Defit ${ }^{2}$, Gunadi Widi Nurcahyo ${ }^{3}$ \\ ${ }^{1,2,3}$ Universitas Putra Indonesia YPTK Padang \\ indahsavitri748@gmai1.com
}

\begin{abstract}
Products provided by a store have an influence on store sales. Consumers will be attracted to stores that provide products according to their wants and needs. The purpose of this research is to find out what ornamental flower products are most in demand by consumers, in demand by consumers and less desirable to consumers. Keywords: inventory of goods, K-Mean Clustering, Data Mining, cluster, optimal. Store managers can get information about goods that have been depleted of inventory stock to be updated immediately. The method used in this study is the K-Mean Clustering method which belongs to one of the branches of Data Mining. The data used in the study is data from January 2020 to December 2020 as many as 100 pieces taken from naafilah official shop, Padang. The data variables used in the entry of goods are the year, product name, price and amount sold. Furthermore, the data is processed using Rapid Miner software. The first stage of processing is to determine the value of clusters randomly, in this study researchers divided the cluster values into 3 groups. Next, the centroid value of each group will be determined. Centroid is derived from the minimum value, middle value and maximum value of the data provided. Then, the cluster process is calculated using the euclidean distance formula. Cluster calculations are done by calculating the closest distance to the data. The final result of this study is to find out the best-selling, best-selling and less-selling ornamental flowers, so that sellers can optimize the provision of ornamental flowers for the future.
\end{abstract}

Keywords: Inventory of Goods, K-Mean Clustering, Data Mining, Cluster, Optimal Sales.

\begin{abstract}
Abstrak
Produk yang disediakan oleh suatu toko memiliki pengaruh terhadap penjualan toko. Konsumen akan tertarik pada toko yang menyediakan produk sesuai dengan keinginan dan kebutuhannya. Tujuan penelitian ini adalah untuk mengetahui produk bunga hias apa saja yang paling diminati konsumen, diminati konsumen dan kurang diminati konsumen. Pengelola toko bisa mendapatkan informasi mengenai barang yang telah habis stok persediaannya agar segera di update. Metode yang digunakan pada penelitian ini adalah metode K-Mean Clustering yang termasuk dalam salah satu cabang Data Mining. Data yang digunakan pada penelitian merupakan data dari Januari 2020 hingga Desember 2020 sebanyak 100 buah yang diambil dari toko Naafilah Official Shop, Padang. Variabel data yang digunakan pada pemasukan barang yaitu tahun, nama produk, harga dan jumlah terjual. Selanjutnya, data tersebut diolah menggunakan software Rapid Miner. Tahapan pengolahan yang pertama adalah menentukan nilai cluster secara acak, dalam penelitian ini peneliti membagi nilai cluster menjadi 3 kelompok. Selanjutnya, nilai centroid dari masing-masing kelompok tersebut akan ditentukan. Nilai centroid diperoleh dari nilai minimum, nilai tengah dan nilai maksimum dari data yang telah disediakan. Lalu, proses cluster dihitung menggunakan rumus euclidean distance. Perhitungan cluster dilakukan dengan menghitung jarak yang paling dekat dengan data. Hasil akhir penelitian ini adalah mengetahui bunga hias yang paling laris, laris dan kurang laris, sehingga penjual dapat mengoptimalkan penyediaan bunga hias untuk masa yang akan datang.
\end{abstract}

Kata Kunci : persediaan barang, K-Mean Clustering, Data Mining, cluster, penjualan optimal.

(C) 2021 JSisfotek

\section{Pendahuluan}

Data yang berukuran besar dapat disimpan dalam database. Database bisa diartikan juga sebagai koleksi data. Kumpulan dari database bisa menjadi Big Data. Big Data merupakan data yang memiliki volume dan kapasitas yang sangat besar sehingga tidak bisa diolah hanya dengan manual dan tradisional, namun butuh proses yang sedemikian rupa agar data tersebut dapat diubah menjadi informasi yang berharga dan dapat dimanfaatkan sesuai yang dibutuhkan [1]. Jadi, Big Data adalah kumpulan data yang sangat besar yang pengolahannya tidak bisa dilakukan secara manual, sehingga membutuhkan cara dan alat agar data tersebut bisa berguna. Dalam perkembangannya, terdapat beberapa metodologi yang dapat digunakan dalam melakukan ektraksi data salah satunya yaitu Knowledge Discovery in Database (KDD). KDD merupakan suatu proses persimpangan dari beberapa disiplin ilmu seperti statistik, database, Artificial Inteligent (AI), visualisasi dan komputer paralel yang mempengaruhi pengetahuan "interdisciplinary knowledge". KDD memliki arti suatu proses pemilihan data, pembersihan data, transformasi data, presentasi, temuan dan evaluasi [2]. KDD adalah suatu metode yang dapat kita gunakan untuk menghasilkan pengetahuan dari database yang ada. Hasil pengetahuan yang telah didapatkan tersebut akan digunakan untuk basis pengetahuan atau knowledge base untuk pengambilan keputusan [3]. 


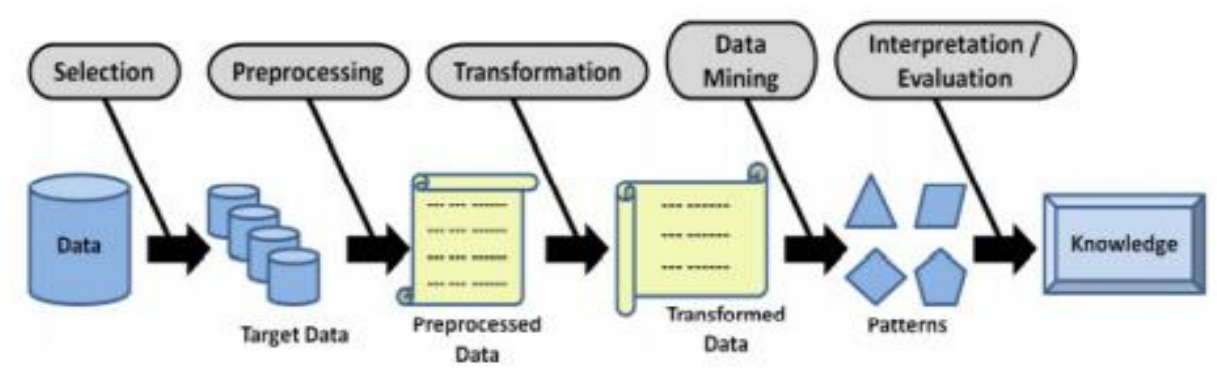

Gambar 1. Proses Knowledge Discovey in Database (KDD)

Menurut Gustientiedina dkk, 2019, adapun proses Knowledge Discovery in Database (KDD) adalah Selection diperlukan untuk menentukan variabel yang akan digunakan agar kesamaan dan perulangan tidak terjadi pada Data Mining; Prepocessing terdapat dua tahap, yang pertama Data Cleaning, yaitu menghilangkan data yang tidak diperlukan seperti menangani missing value, noise data dan menangani data - data yang tidak konsisten serta relevan, kedua Data Integration, yaitu dilakukan terhadap atribut yang mengidentifikasikan entitas yang unik; Transformation; data dirubah sesuai format ekstention yang sesuai dalam pengolahan Data Mining, karena beberapa metode pada Data Mining memerlukan format khusus sebelum dilakukan pemrosesan; Data Mining; merupakan proses utama pada metode yang diterapkan untuk mendapatkan pengetahuan baru dari data yang diproses; Evaluation/Interpretation yang dilakukan identifikasi terhadap pola-pola yang menarik kedalam knowledge base yang akhirnya akan menghasilkan pola-pola khas maupun model prediksi yang dievaluasi untuk menilai kajian yang ada, apakah sudah memenuhi target yang diinginkan atau belum; Knowledge yaitu pengetahuan baru yang dihasilkan bisa dipahami semua orang sehingga pengetahuan tersebut bisa dijadikan sebagai acuan pengambilan keputusan dan pola-pola yang dihasilkan akan dipresentasikan kepada pengguna.

Salah satu tahapan dalam keseluruhan proses KDD adalah Data Mining [4]. Mining diartikan sebagai usaha untuk mendapatkan sedikit barang berharga dari sejumlah besar material dasar [1]. Mining merupakan proses informasi yang dilakukan dari database yang dapat dilakukan meskipun tidak terlihat [5]. Data Mining adalah suatu rangkaian proses yang mengolah kumpulan data yang berlimpah untuk mengggali informasi yang belum diketahui dengan cara mengenali pola-pola data dari informasi tersebut [6]. Salah satu metode yang termasuk dalam Data Mining adalah clustering. Clustering atau pengelompokan adalah alat yang digunakan dalam ilmu data [7], [8], [9]. Secara umum, cluster adalah sekelompok objek yang lebih mirip satu sama lain daripada anggota cluster lain [10]. Salah satu algoritma yang digunakan dalam clustering adalah K-Mean. Algoritma K-Means adalah metode iterasi sederhana untuk mempartisi set data yang diberikan ke dalam jumlah cluster yang ditentukan pengguna [6]. Tujuan pengelompokkan data adalah untuk meminimalkan fungsi objektif yang diatur dalam proses pengelompokan, pada umumnya berusaha meminimalkan variasi suatu kelompok dan memaksimalkan variasi antar kelompok. Algoritma KMean Cluster menggunakan analisa pengklasteran dengan Non-Hirarcial Cluster, metode ini dimulai dari pengambilan cluster yang diinginkan terlebih dahulu, cluster yang diambil bisa saja dua cluster, tiga cluster atau cluster yang lain hingga terbentuknya cluster [11].

Usaha Mikro, Kecil dan Menengah (UMKM) memiliki pelanggan dan memiliki stok produk dalam jumlah yang banyak, namun UMKM tidak memiliki pemetaan pelanggan dan stok produk sehingga mereka tidak tahu produk apa saja yang menjadi favorit pelanggan [9]. Konsumen akan tertarik pada toko yang menyediakan produk sesuai dengan keinginan dan kebutuhannya [4].

\section{Metodologi Penelitian}

Data yang digunakan pada penelitian ini adalah data penjualan bunga hias yang diperoleh dari UMKM Nafiilah Official Shop, Padang. Pada data ini terdapat informasi yaitu hari, tanggal, bulan, tahun, nama bunga, harga, stok dan jumlah terjual.

Metodologi pengolahan data yang digunakan adalah Data Mining dengan metode K-Mean Clustering. Pada tahap analisa data, data yang dibutuhkan adalah data dalam bentuk Microsoft Excel, namun data yang didapat dari toko Nafiilah Official Shop adalah data dalam bentuk pembukuan sehingga perlu dilakukan perekapan ulang ke bentuk Microsoft Excel lalu menggunakan rumus euclidean distance dan software Rapid Miner. Setelah melakukan pengolahan dan perhitungan data, maka didapatlah hasil cluster yang diinginkan. Maka dilakukan penelitian ini dengan tahapan yang disajikan pada kerangka penelitian pada Gambar 2 . 


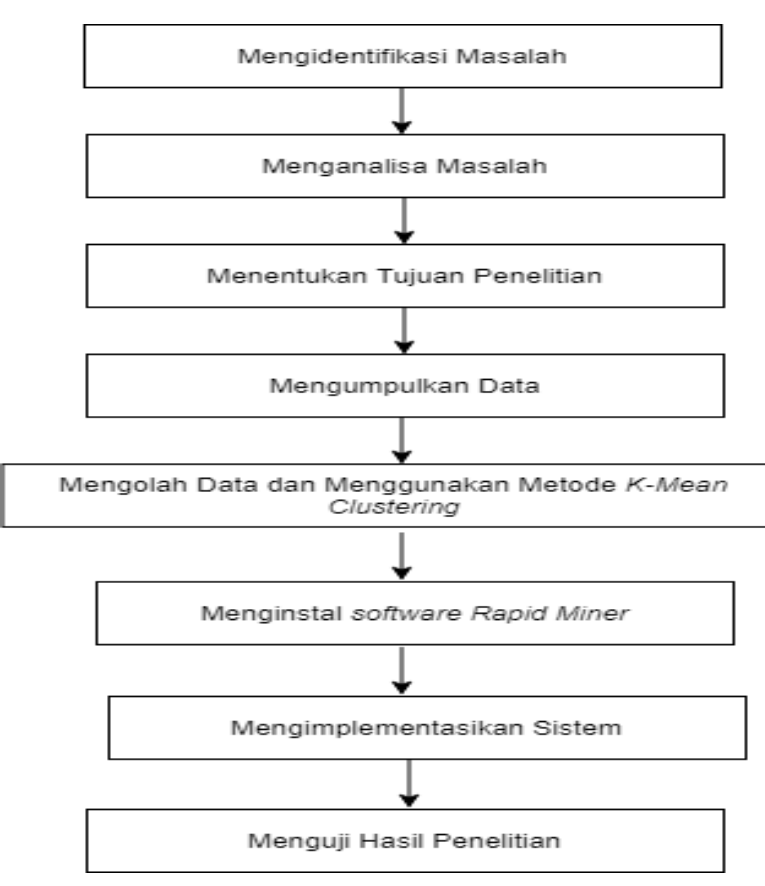

Gambar 2. Kerangka Kerja Penelitian

Langkah-langkah yang dilakukan unutk membentuk clustering pada metode K-Mean Clustering adalah:

a. Memilih nilai cluster awal secara acak.

b. Setiap data dalam dataset dibagi kedalam beberapa kelompok cluster antara setiap titik dan pusat cluster yang didapatkan berdasarkan jarak euclidean distance. Adapun rumus euclidean distance disajikan pada Persamaan (1).

$$
J=\sqrt{(n i-m i)^{2}+(n j-m j)^{2}}
$$

Di mana $\mathrm{J}$ sebagai jarak data ke pusat cluster, $\mathrm{n}$ sebagai data ke- pada atribut ke-, dan m sebagai titik pusat ke-, pada atribut.

c. Setiap pusat cluster dihitung ulang berdasarkan dari nilai rata-rata dalam cluster yang didapatkan. Adapun rumus untuk menentukan nilai centroid baru disajikan pada PErsamaan (2).

$$
c d=\frac{c 1+c n}{d c}
$$

Di mana Cd sebagai nilai centorid yang ingin ditentukan, c1 sebagai nilai cluster pada data $1, \mathrm{cn}$ sebagai nilai cluster pada data ke 2, 3, 10, 50, dst dan dc sebagai jumlah data per cluster. Dengan kata lain, untuk menentukan nilai centroid, peneliti dapat mencari nilai rata-rata per cluster.

d. Ulangi langkah 2 dan 3 sampai kelompok tersebut sesuai. Perulangan dapat didefinisikan secara berbeda tergantung pada implementasi, tetapi biasanya pada proses langkah 2 dan 3 dapat diulangi apabila kelompok cluster masih mengalami perubahan dan proses akan terhenti apabila tidak ada perubahan nilai antar cluster.

\section{Hasil dan Pembahasan}

\subsection{Analisa Data}

Jumah data yang digunakan dalam penelitian ini sebanyak 100 data. Output yang diinginkan dari penelitian ini adalah 3 cluster, yaitu barang yang paling laris, laris dan kurang laris. Atribut yang digunakan dalam perhitungan data adalah nama barang, stok dan jumlah terjual.

\subsection{Perhitungan Metode K-Mean Clustering}

Untuk melakukan cluster data, hal pertama yang dilakukan adalah menetukan jumlah cluster. Cluster pertama ditentukan secara acak, pada penelitian ini, peneliti menagambil dari data ke 5, 46 dan 80. Adapun cluster pertama yang digunakan seperti Tabel 1 .

Tabel 1. Claster pertama

\begin{tabular}{lcc}
\hline Cluster & Stok & Jumlah Terjual \\
\hline Cluster 1 & 10 & 85 \\
Cluster 2 & 10 & 412 \\
Cluster 3 & 12 & 199 \\
\hline
\end{tabular}

Cluster pertama akan diolah menggunakan rumus euclidean distance seperti persamaan 1, lalu hitung jarak dari data 1 hingga 100. Namun, dalam perhitungan ini peneliti hanya memberikan sampel data ke 1 hingga data ke 3, sehingga didapatlah hasil cluster data untuk cluster 1, cluster 2 dan cluster 3.

a. Menghitung Jarak Dari Data Ke 1 Terhadap Pusat Cluster

$\mathrm{C} 1=\sqrt{(12-10)^{2}+(10-85)^{2}}=75$

$\mathrm{C} 2=\sqrt{(12-10)^{2}+(10-412)^{2}}=402$

$\mathrm{C} 3=\sqrt{(12-12)^{2}+(10-199)^{2}}=189$

b. Menghitung Jarak Dari Data Ke 2 Terhadap Pusat Cluster

$\mathrm{C} 1=\sqrt{(10-10)^{2}+(2-85)^{2}}=83$

$C 2=\sqrt{(10-10)^{2}+(2-412)^{2}=410}$

$\mathrm{C} 3=\sqrt{(10-12)^{2}+(2-199)^{2}}=197$

c. Menghitung Jarak Dari Data Ke 3 Terhadap Pusat Cluster

$\mathrm{C} 1=\sqrt{(10-10)^{2}+(5-85)^{2}}=80$

$C 2=\sqrt{(10-10)^{2}+(5-412)^{2}}=407$

$\mathrm{C} 3=\sqrt{(10-12)^{2}+(5-199)^{2}}=194$

Berdasarkan hasil perhitungan jarak data dengan pusat cluster, maka hasil yang didapatkan oleh masingmasing cluster. Hasil cluster dari iterasi 1 adalah:

$\mathrm{C} 1=1,2,3,4,5,7,8,9,10,11,12,13,14,15,16,17$, $19,22,23,24,25,26,27,28,29,31,32,33,34$, $35,37,38,40,41,42,43,44,45,47,48,49,50$, $53,54,56,57,58,59,60,61,62,63,64,65,66$, $67,69,71,72,73,75,76,77,79,81,82,83,85$, $87,88,90,91,92,93,95,96,97,98,99,100$. 
$\mathrm{C} 2=6,46,55,68,94$.

$\mathrm{C} 3=18,20,21,30,36,39,51,52,70,78,80,84,86$, 89.

Selanjutnya adalah menghitung nilai pusat cluster atau nilai centroid baru untuk masing-masing menggunakan rumus sesuai dengan Persamaan (2). Nilai centroid didapatkan dari nilai rata-rata masing-masing cluster yang telah dilakukan pada iterasi 1 sebelumnya. Berikut hasil nilai centroid seperti Tabel 2.

Tabel 2. Cluster Kedua

\begin{tabular}{lrc}
\hline Cluster & Stok & Jumlah Terjual \\
\hline Cluster 1 & 8,89 & 29,38 \\
Cluster 2 & 11,4 & 513 \\
Cluster 3 & 9,86 & 208 \\
\hline
\end{tabular}

Cluster kedua diolah menggunakan rumus euclidean distance, lalu hitung jarak dari data 1 hingga 100 . Namun, dalam perhitungan ini peneliti hanya memberikan sampel data ke 1 hingga data ke 3 , sehingga didapatlah hasil cluster data untuk cluster 1, cluster 2 dan cluster 3.

a. Menghitung Jarak Dari Data Ke 1 Terhadap Pusat Cluster

$\mathrm{C} 1=\sqrt{(12-8,89)^{2}+(10-29,38)^{2}}=20$

$\mathrm{C} 2=\sqrt{(12-11,4)^{2}+(10-513)^{2}}=503$

$\mathrm{C} 3=\sqrt{(12-9,86)^{2}+(10-208)^{2}}=198$

b. Menghitung Jarak Dari Data Ke 2 Terhadap Pusat Cluster

$\mathrm{C} 1=\sqrt{(10-8,89)^{2}+(2-29,38)^{2}}=27$

$\mathrm{C} 2=\sqrt{(10-11,4)^{2}+(2-513)^{2}}=511$

$\mathrm{C} 3=\sqrt{(10-11,4)^{2}+(2-513)^{2}}=206$

c. Menghitung Jarak Dari Data Ke 3 Terhadap Pusat Cluster

$$
\begin{aligned}
& \mathrm{C} 1=\sqrt{(10-8,89)^{2}+(5-29,38)^{2}}=24 \\
& \mathrm{C} 2=\sqrt{(10-11,4)^{2}+(5-513)^{2}}=508 \\
& \mathrm{C} 3=\sqrt{(10-11,4)^{2}+(5-513)^{2}}=203
\end{aligned}
$$

Hasil perhitungan yang didapatkan dari masing-masing cluster menghasilkan cluster dari iterasi 2 yaitu:

$\mathrm{C} 1=1,2,3,4,5,7,8,9,10,11,13,14,15,16,17,19$, $22,23,24,25,26,27,28,29,31,33,34,35,37$, $38,40,41,42,43,44,45,47,48,49,50,53,54$, $56,57,58,59,60,61,62,63,64,65,66,67,69$, $71,72,73,75,76,77,79,81,82,83,85,87,88$, 90, 91, 92, 93, 95, 96, 97, 98, 99, 100.

$\mathrm{C} 2=46,55,68,94$.

$\mathrm{C} 3=6,12,18,20,21,30,32,36,39,51,52,70,74,78$, $80,81,84,86,89,96$.

Setelah didapatkan hasil iterasi 2, peneliti dapat Iterasi 1 dan iterasi 2 menghasilkan nilai cluster yang

membandingkan hasil cluster iterasi 1 dan iterasi 2, sama. Maka, proses K-Mean selesai. Jadi, kesimpulan pada penelitian ini menghasilkan nilai cluster yang berbeda, yaitu pada data 6, 12, 32, 74, 81 dan 96 . Maka, peneliti harus melakukan perulangan iterasi agar nilai cluster per data tidak lagi berubah. Untuk menentukan nilai centroid baru iterasi ketiga, cara yang digunakan sama dengan menentukan nilai centroid pada iterasi 2. Pada iterasi ketiga, peneliti menentukan nilai rata-rata per cluster dari iterasi 2. Berikut hasil nilai centroid seperti Tabel 3.

Tabel 5. Cluster Ketiga

\begin{tabular}{ccc}
\hline Cluster & Stok & Jumlah Terjual \\
\hline Cluster 1 & 11 & 31 \\
Cluster 2 & 10 & 511 \\
Cluster 3 & 10 & 202 \\
\hline
\end{tabular}

Setiap data akan dihitung menggunakan rumus euclidean dstance seperti persamaan 1, data dihitung dari data 1 hingga data 100.

a. Menghitung Jarak Dari Data Ke 1 Terhadap Pusat Cluster

$$
\begin{aligned}
& \mathrm{C} 1=\sqrt{(12-11)^{2}+(10-31)^{2}}=21 \\
& \mathrm{C} 2=\sqrt{(12-10)^{2}+(10-551)^{2}}=541 \\
& \mathrm{C} 3=\sqrt{(12-10)^{2}+(10-202)^{2}}=192
\end{aligned}
$$

b. Menghitung Jarak Dari Data Ke 2 Terhadap Pusat Cluster

$$
\begin{aligned}
& \mathrm{C} 1=\sqrt{(10-11)^{2}+(2-31)^{2}}=29 \\
& \mathrm{C} 2=\sqrt{(10-10)^{2}+(2-551)^{2}}=549 \\
& \mathrm{C} 3=\sqrt{(10-10)^{2}+(2-202)^{2}}=200
\end{aligned}
$$

c. Menghitung Jarak Dari Data Ke 3 Terhadap Pusat Cluster

$$
\begin{aligned}
& \mathrm{C} 1=\sqrt{(10-11)^{2}+(5-31)^{2}}=26 \\
& \mathrm{C} 2=\sqrt{(10-10)^{2}+(5-551)^{2}}=546 \\
& \mathrm{C} 3=\sqrt{(10-10)^{2}+(5-202)^{2}}=197
\end{aligned}
$$

Hasil perhitungan cluster dari iterasi 3 adalah:

$\mathrm{C} 1=1,2,3,4,5,7,8,9,10,11,13,14,15,16,17,19$, $22,23,24,25,26,27,28,29,31,33,34,35,37$, $38,40,41,42,43,44,45,47,48,49,50,53,54$, $56,57,58,59,60,61,62,63,64,65,66,67,69$, $71,72,73,75,76,77,79,81,82,83,85,87,88$, $90,91,92,93,95,96,97,98,99,100$.

$\mathrm{C} 2=46,55,68,94$.

$\mathrm{C} 3=6,12,18,20,21,30,32,36,39,51,52,70,74$, $78,80,81,84,86,89,96$. 
dari hasil clustering menggunakan Microsft Excel yaitu sebagai berikut:

a. Bunga hias yang paling laris adalah pada cluster 2, yaitu data ke 46, 55, 68 dan 94.

b. Bunga hias yang laris adalah pada cluster 3, yaitu data ke $6,12,18,20,21,30,32,36,39,51,52,70$, 74, 78, 80, 81, 84, 86, 89 dan 96.

c. Bunga hias yang kurang laris adalah pada cluster 1 , yaitu data ke 1, 2, 3, 4, 5, 7, 8, 9,10, 11, 13, 14, 15,
$16,17,19,22,23,24,25,26,27,28,29,31,33,34$, $35,37,38,40,41,42,43,44,45,47,48,49,50,53$, $54,56,57,58,59,60,61,62,63,64,65,66,67,69$, $71,72,73,75,76,77,79,81,82,83,85,87,88,90$, 91, 92, 93, 95, 96, 97, 98, 99, 100.

\subsection{Hasil Pengujian Data.}

Hasil pengujian data ditampilkan plot yang disajikan pada Gambar 3.

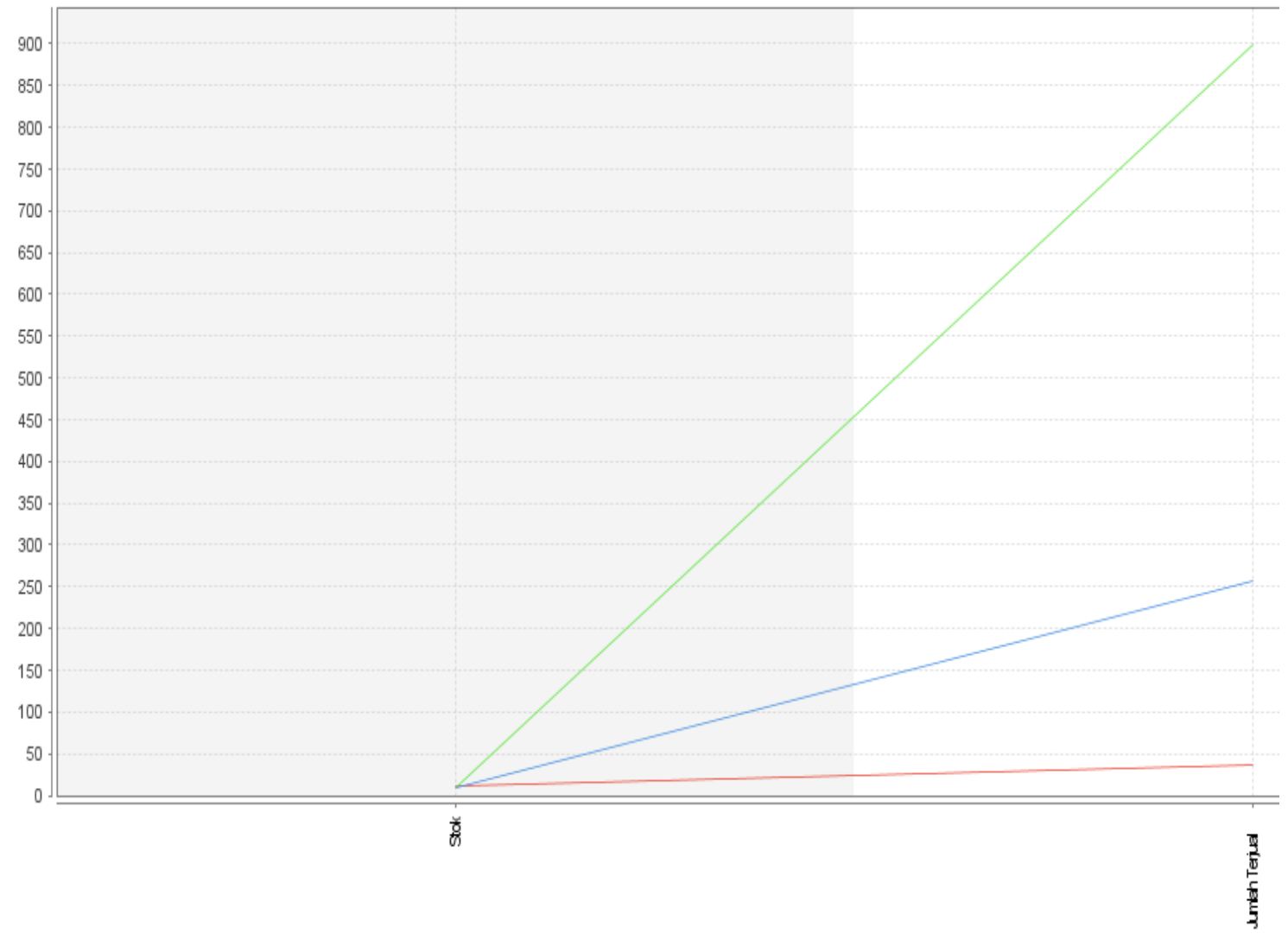

Gambar 3. Hasil Plot

Gambar 3. menguraikan bahwa garis ditarik dari arah sebelah kiri (stok) menuju sebelah kanan (jumlah terjual). Garis berwarna hijau menunjukkan cluster 1, garis berwarna biru menunjukkan cluster 0 dan garis berwarna merah menunjukkan cluster 2 . Pada tampilan Plot, garis berwarna hijau disebut sebagai cluster 1 pada Microsoft Excel, garis berwarna biru disebut sebagai cluster 3 pada Microsoft Excel dan garis warna merah disebut cluster 2.

Hasil clustering adalah berikut:

a. Bunga hias yang paling laris terdapat pada cluster 1 , yaitu data ke 94 .

b. Bunga hias yang laris terdapat pada cluster 0 , yaitu data ke $6,18,20,21,30,36,39,46,52,55,68,70$, $74,78,80,84,86$ dn 89 .

c. Bunga hias yang kurang laris terdapat pada cluster 2 , yaitu data ke 1, 2, 3, 4, 5, 7, 8, 10, 12, 13, 14, 15, 16,
$17,19,22,23,24,25,26,27,28,29,31,32,33,34$, $35,37,38,40,41,42,43,44,45,47,48,49,50,51$, $53,54,56,57,58,59,60,61,62,63,64,65,67,68$, $71,72,73,75,76,77,79,81,82,83,85,87,88,90$, 91, 92, 93, 95, 97, 98, 99 dan 100 .

\section{Kesimpulan}

Metode K-Mean Clustering dapat digunakan untuk simulasi pengadaan penjualan produk bunga hias. Metode K-Mean Clustering dapat memberikan rekomendasi bunga hias yang paling laris, laris dan kurang laris, sehingga bisa dijadikan pedoman kepada pemilik toko untuk persediaan barang di masa yang akan datang.

\section{Daftar Rujukan}

[1] Mirantika, N. (2021). Penerapan Algoritma K-Means Clustering Untuk Pengelompokan Penyebaran Covid-19 di Provinsi Jawa Barat. Nuansa Informatika, 15(2), 92-98. doi:10.25134/nuansa.v15i2.4321 
[2] Ependi, U., \& Putra, A. (2019). Solusi Prediksi Persediaan Barang dengan Menggunakan Algoritma Apriori (Studi Kasus: Regional Part Depo Auto 2000 Palembang). Jurnal Edukasi Dan Penelitian Informatika (JEPIN), 5(2), 139. doi:10.26418/jp.v5i2.32648

[3] Gustientiedina, G., Adiya, M. H., \& Desnelita, Y. (2019). Penerapan Algoritma K-Means Untuk Clustering Data ObatObatan. Jurnal Nasional Teknologi Dan Sistem Informasi, 5(1), 17-24. doi:10.25077/teknosi.v5i1.2019.17-24

[4] Kamila, I., Khairunnisa, U., \& Mustakim, M. (2019). Perbandingan Algoritma K-Means dan K-Medoids untuk Pengelompokan Data Transaksi Bongkar Muat di Provinsi Riau. Jurnal Ilmiah Rekayasa Dan Manajemen Sistem Informasi, 5(1), 119. doi:10.24014/rmsi.v5i1.7381

[5] Sinaga, K. P., \& Yang, M.-S. (2020). Unsupervised K-Means Clustering Algorithm. IEEE Access, 8, 80716-80727. doi:10.1109/access.2020.2988796

[6] Astuti, D. (2019). Penentuan Strategi Promosi Usaha Mikro Kecil Dan Menengah (UMKM) Menggunakan Metode CRISPDM dengan Algoritma K-Means Clustering. Journal of Informatics, Information System, Software Engineering and $\begin{array}{lll}\text { Applications } & \text { (INISTA), } & \text { 60-72. }\end{array}$ doi:10.20895/inista.v1i2.71
[7] Yang, M.-S., \& Sinaga, K. P. (2019). A Feature-Reduction Multi-View k-Means Clustering Algorithm. IEEE Access, 7, 114472-114486. doi:10.1109/access.2019.2934179

[8] Syakur, M. A., Khotimah, B. K., Rochman, E. M. S., \& Satoto, B. D. (2018). Integration K-Means Clustering Method and Elbow Method For Identification of The Best Customer Profile Cluster. IOP Conference Series: Materials Science and Engineering, 336, 012017. doi:10.1088/1757899x/336/1/012017

[9] Singh, S., \& Singh, P. (2020). Speaker specific feature based clustering and its applications in language independent forensic speaker recognition. International Journal of Electrical and Computer Engineering (IJECE), 10(4), 3508. doi:10.11591/ijece.v10i4.pp3508-3518

[10] Rachma, A., Aden, A., \& Rusdiana, Y. (2019). Analisis Cluster Menggunakan Algoritma K-Means Cluster Untuk Culstering Jenis Penyakit Menular Pada Puskesmas Di Kecamatan Kota Tangerang. Jurnal Saintika Unpam: Jurnal Sains Dan Matematika Unpam, 2(1), 15. doi:10.32493/jsmu.v2i1.2915

[11] Sinaga, L., Ahmad, A., \& Safii, M. (2019). Penerapan Data Mining Pada Jumlah Pelanggan Perusahaan Air Bersih Menurut Provinsi Menggunakan Metode K-Means Clustering. Jurnal RESISTOR (Rekayasa Sistem Komputer), 2(2), 119125. doi:10.31598/jurnalresistor.v2i2.418. 